\title{
Gastric Marginal Zone Lymphoma of Mucosa-Associated Lymphoid Tissue and Signet Ring Cell Carcinoma, Synchronous Collision Tumour of the Stomach: A Case Report
}

\author{
Smiley Annie George ${ }^{a} \quad$ T.A. Junaid ${ }^{a, b}$ \\ Department of a Histopathology, Mubarak Al-Kabir Hospital, and b Department of Pathology, Faculty of Medicine, \\ Kuwait University, Jabriya, Kuwait
}

\section{Key Words}

Mucosa-associated lymphoid tissue lymphoma .

Adenocarcinoma $\cdot$ Collision $\cdot$ Stomach

\begin{abstract}
Objective: To report a rare case of synchronous marginal zone lymphoma of mucosa-associated lymphoid tissue (MALT) signet ring cell carcinoma occurring as a collision tumour in the stomach. Clinical Presentation and Intervention: A 53-yearold man was diagnosed initially with signet ring cell carcinoma of the stomach. The microscopy of the subsequent total gastrectomy revealed a collision tumour of MALT lymphoma and signet ring cell carcinoma associated with Helicobacter pylori gastritis. Conclusion: This case highlighted the importance of a careful evaluation of the accompanying lymphoid population in the biopsy samples of gastric adenocarcinoma and underlined the need for multiple endoscopic biopsies to detect these rare synchronous tumours.
\end{abstract}

(c) 2013 S. Karger AG, Basel

\section{Introduction}

The occurrence of primary multiple malignancies arising from different tissue in the same organ and patient is very rare. The majority of gastric tumours are carcino-

\begin{tabular}{|c|c|}
\hline KARGER & $\begin{array}{l}\text { (c) } 2013 \text { S. Karger AG, Basel } \\
1011-7571 / 13 / 0234-0377 \$ 38.00 / 0\end{array}$ \\
\hline $\begin{array}{l}\text { E-Mail karger@karger.com } \\
\text { www.karger.com/mpp }\end{array}$ & $\begin{array}{l}\text { This is an Open Access article licensed under the terms of the } \\
\text { Creative Commons Attribution-NonCommercial 3.0 Un- } \\
\text { ported license (CC BY-NC) (www.karger.com/OA-license), } \\
\text { applicable to the online version of the article only. Distribu- } \\
\text { tion permitted for non-commercial purposes only. }\end{array}$ \\
\hline
\end{tabular}

mas, whereas lymphomas constitute $1-7 \%$ of all malignant tumours of the stomach [1]. The simultaneous coexistence of an adenocarcinoma associated with a malignant lymphoma in the stomach is a rare entity but is well known [1-4]. In such cases, problems may arise with the initial diagnosis and inadequate endoscopic biopsy may make separation of reactive from neoplastic lymphoid tissue or lymphoma from poorly differentiated carcinoma difficult [3]. Additionally, the co-existence of the two tumours may bring up the question of the sequence of events and the role of aetiological agents in their causation.

We report here a case of co-existing mucosa-associated lymphoid tissue (MALT) lymphoma and signet ring carcinoma with Helicobacter pylori infection in the stomach, which brought into focus the problems often encountered in such rare instances.

\section{Case Report}

A 53-year-old man presented to the Surgical Outpatient Department with a 2-month history of rectal bleeding, black tarry stools and associated episodes of fainting. His past medical history was unremarkable. There was no family history of gastrointestinal disease. Physical examination revealed pallor. Haematological investigations showed normocytic anaemia and thrombocytopenia: other haematological and biochemical parameters were normal. A 


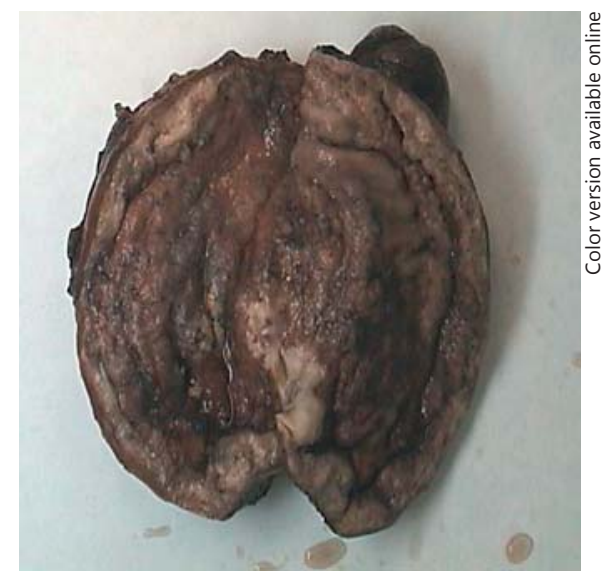

Fig. 1. Surgical specimen showing the gastric wall diffusely thickened and ulcerated.

computed tomographic (CT) scan of the abdomen and pelvis showed a diffusely thickened stomach wall suggestive of linitis plastica with perigastric lymphadenopathy. Multiple osteolytic lesions were noted in the dorso-lumbar vertebrae. Endoscopy showed a big fundal mass infiltrating the greater curvature up to one third of the stomach.

Histopathological examination of the gastric biopsy was reported as infiltrating adenocarcinoma of the signet ring cell type and was negative for $H$. pylori infection. Bone scintigraphy and bone marrow examination showed no evidence of metastasis. The patient was given a total of 4 sessions of chemotherapy ( $5 \mathrm{FU}+$ leucovorin LF1) with 3-week intervals between each session. Anti- $H$. pylori treatment was not given as the initial gastric biopsy was negative for the same. A follow-up contrast-enhanced CT scan of the abdomen and the pelvis showed an ulcerated irregular heterogeneous soft tissue density mass $(9 \times 7 \times 6 \mathrm{~cm})$ in the body of the stomach, causing circumferential irregular wall thickening extending towards the gastric fundus with perigastric lymphadenopathy. An endoscopy showed the upper margin of the previously diagnosed gastric tumour reaching the gastro-oesophageal junction. A PET-CT scan revealed increased uptake of the tracer FDG within the stomach lesion.

In view of the disease progression and unresponsiveness to chemotherapy, a total gastrectomy was performed. The gastrectomy measured $35.5 \mathrm{~cm}$ along the greater curvature and $11.5 \mathrm{~cm}$ along the lesser curvature and showed a diffusely thickened wall with ulcerated mucosa involving fundus to antrum (fig. 1). The resection margins appeared free from the lesion. Lymph nodes were dissected along the lesser and greater curvatures. The related histopathological findings showed intermingled areas of poorly differentiated signet ring cell carcinoma and diffuse monotonous sheets and nodules of small lymphoid cells with centrocyte morphology (fig. 2). There was transmural involvement of the gastric wall by both components. At immunohistochemical assay, the lymphoid cells were diffusely positive for CD20 (fig. 3) and BCL2

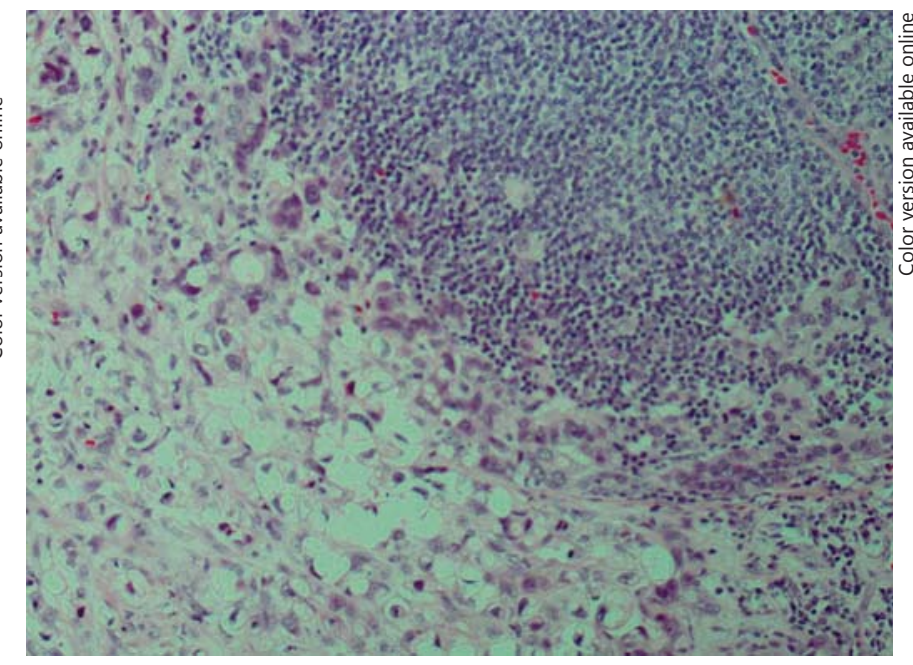

Fig. 2. High-power histopathological analysis of gastric tissue showing the concomitant presence of a signet ring cell carcinoma associated with MALT-lymphoma. HE. ×400.

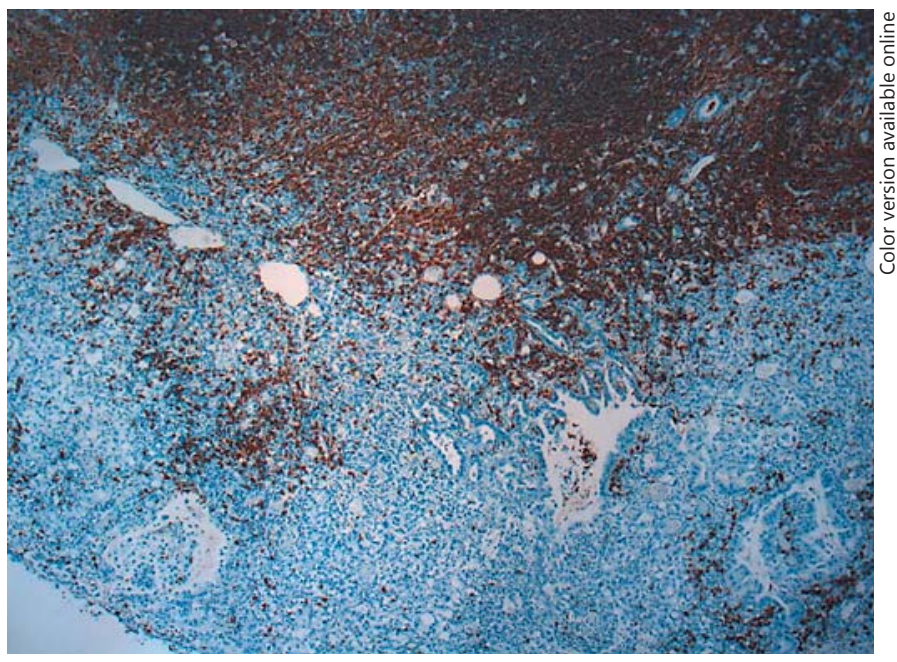

Fig. 3. Histopathological analysis of gastric tissue, in which lymphoid cells show a strong positivity for CD20 at immunohistochemical assay. HE. $\times 200$.

and focally positive for CD43. They were negative for CD10, cyclin D1, CD5, CD23 and Bcl-6. The Ki-67 proliferation index was 5\%. Of the 60 perigastric lymph nodes, 54 (90\%) showed metastatic carcinoma. The adjacent gastric mucosa showed severe chronic active $H$. pylori (Warthin-Starry stain and $H$. pylori immunostain positive) associated gastritis with intestinal metaplasia. The lesser omental margin was positive for signet ring cell carcinoma. The carcinomatous areas showed no definite response (grade 3) to chemotherapy. A final diagnosis of a collision tumour, signet ring cell carcinoma and MALT lymphoma (ypT4aN3bMx) was made. The 
pre-operative biopsy was reviewed and it showed foci of signet ring cell carcinoma admixed with a monotonous lymphoid population whose features were consistent with MALT lymphoma. The patient survived the immediate post-operative period and had a follow-up endoscopy 2 months later, which showed an inflammatory polyp at the anastomotic site confirmed at biopsy. Thereafter, the patient was lost to follow-up.

\section{Discussion}

The intimate admixture of the low-grade MALT lymphoma and the poorly differentiated signet ring cell carcinoma without any normal gastric mucosa or clear-cut macroscopic separation makes them collision tumours $[1,3,5,6]$. What is uncertain, however, is whether they developed together (i.e. synchronous) or followed one another (metachronous). The earlier report of the endoscopic gastric biopsy solely as a signet ring carcinoma and the subsequent treatment of the patient with chemotherapy would appear to provide support for a metachronous origin. Contrarily, the review of the endoscopic slides, which showed that both a MALT lymphoma and a signet ring carcinoma were present together but that the lymphoid infiltrate had been misinterpreted as 'reactive', does not support metachronous tumours. Further support is given to a synchronous development by the widespread involvement of the gastric wall by both tumours because when they arise at different time events, the second tumour tends to be smaller and less advanced [4].

The presence of $H$. pylori in the gastrectomy specimen points to a possible aetiological agent for our patient's tumours as this class- 1 carcinogen is recognized as a common aetiological agent for the synchronous occurrence of gastric MALT lymphoma and adenocarcinoma [3, 4, 7, 8]. Although most of the latter have been of the intestinal type, with other types being rare, few cases of synchronous signet ring cell carcinoma, such as in this case, have been reported [3]. However, not all cases of synchronous gastric MALT lymphoma and adenocarcinoma are associated with $H$. pylori. Other possible aetiopathogenetic causes such as EBV, genetic susceptibility, chemoradiotherapy and exposure to radiation continue to be explored [3].

MALT lymphoma and poorly differentiated adenocarcinoma show a macroscopic and microscopic resemblance, and, as in this case, reactive lymphoid infiltrate may be difficult to distinguish from MALT lymphoma [3, $4,9]$. To minimize such errors, it is important that multiple endoscopic gastric biopsies be taken at different sites and from all suspicious areas.

\section{Conclusion}

This case highlighted the importance of a careful evaluation of the accompanying lymphoid population in the biopsy samples of gastric adenocarcinoma and underlined the need for multiple endoscopic biopsies to detect these rare synchronous tumours.

\section{Acknowledgement}

We acknowledge the contributions of the Departments of Radiology and Nuclear Medicine.

\section{References}

1 Nakamura S, Aoyagi K, Iwanaga S, et al: Synchronous and metachronous primary gastric lymphoma and adenocarcinoma: a clinicopathological study of 12 patients. Cancer 1997;79:1077-1085, comment 1998;82:226227.

- Noda T, Akashi H, Matsueda S, et al: Collision of malignant lymphoma and multiple early adenocarcinomas of stomach. Arch Pathol Lab Med 1989;113:419-422.

3 Lee S-Y, Kim JJ, Lee JH, et al: Synchronous adenocarcinoma and mucosa-associated lymphoid tissue (MALT) lymphoma in a single stomach. Jpn J Clin Oncol 2005;35:591594.
4 Wotherspoon C, Isaacson PG: Synchronous adenocarcinoma and low grade B-cell lymphoma of mucosa associated lymphoid tissue (MALT) of the stomach. Histopathology 1995;27:325-331.

5 Manier JW, Reyes CN: Collision tumour of the stomach: report of two cases. Gastroenterology 1974;67:1011.

6 Hamaloglu E, Topaloglu S, Ozdemir A, et al: Synchronous and metachronous occurrence of gastric adenocarcinoma and gastric lymphoma: a review of the literature. World J Gastroenterol 2006;12:3564-3574.
7 Muller S, Seifert E, Stolte M: Simultaneous MALT type lymphoma and early adenocarcinoma of stomach associated with Helicobacter pylori gastritis. Z Gastroenterol 1999; 37:153-157.

$>8$ Zucca E, Bertoni F, Roggero E, et al: The gastric marginal zone B cell lymphoma of MALT type. Blood 2000;96:410-419.

9 Chan AO, Chu KM, Yuen ST, et al: Synchronous gastric adenocarcinoma and mucosaassociated lymphoid tissue lymphoma in association with Helicobacter pylori infection: comparing reported cases between the East and West. Am J Gastroenterol 2001;96:19221924.
Gastric MALT Lymphoma and Signet

Ring Cell Carcinoma of the Stomach
Med Princ Pract 2014;23:377-379 DOI: $10.1159 / 000356180$ 